Fairbairn, W.R.D. (1952). Psychoanalytic Studies of the Personality. Boston: Routledge Kegan Paul.

Winnicott, D. (1958). Collected Papers: Through Pediatrics to Psychoanalysis. New York: Basic Books.

Ghislaine Boulanger

242 West 101 Street, New York, NY 10025, USA.

\title{
Reply to Ghislaine Boulanger
}

Psychoanalysis, Culture \& Society (2008) 13, 120.

doi:10.1057/palgrave.pcs.2100155

I 'm sorry that what I regard as a basically positive review has been interpreted so negatively. Boulanger's assertion that I have an antipathy to relational psychoanalysis is distressing. As paragraph two of my review makes clear, my concern is with defects that I find in classical psychoanalysis, Lacanian psychoanalysis, and relational psychoanalysis. Disagreement is not antipathy, and in any case my critical lens points in many directions. But to stick to the basics: (1) the self is a defense mechanism constructed to flee reality. To say that movement from an old self to a new self - that is, the "reconstituting a self" - is the goal of therapy, as Boulanger does, is to commit oneself to restoring avoidance, illusion, and denial as preeminent human needs. (2) To the twice quoted claim of Thomas Ogden that it is impossible to maintain our sanity and genuinely experience our mortality, Boulanger has now added the authority of Becker, Winnicott, and Fairbairn. That duly noted, I would submit that the claim is false. Some, perhaps many, people find no difficulty accepting mortality (and being more sane as a result). What Boulanger's position really points to is the general need of relational thinkers to minister to our fears under the guise of giving us things we can't live without. (3) Finally, with respect to Lacan, the point is philosophic. Lacanian thought and relational thought rest on incompatible theoretical foundations. Accordingly, to take any concept from one of them and incorporate it into the other is to bastardize it. It may make for some sense that we're all in some way in agreement but it does so by destroying central theoretical and philosophic issues that must be preserved.

Which is another way of saying that one purpose of a review should be to interrogate a book in order to engage its contradictions. It was in that spirit that I wrote what I hoped would be a helpful review. I am saddened that Ghislaine Boulanger did not take it that way.

Walter A. Davis, Ohio State University 209 S. Third St., Grand Haven, MI 49417, USA. E-mail: davis.65@osu.edu 